\title{
Unnecessary life threatening complications after IVF in mixed connective tissue disease
}

\author{
Zeev Blumenfeld
}

Received: 12 March 2012 / Accepted: 26 March 2012 /Published online: 11 April 2012

(C) Springer Science+Business Media, LLC 2012

I have read with great interest the recent demonstrative case report by Sioulas \& Gracia on ovarian stimulation and embryo banking for fertility preservation in a woman with severe mixed connective tissue disease [MCTD] [1], and congratulate the authors for their integrity and self criticism. The authors correctly emphasize the life threatening complications associated with pulmonary hypertension and IVF in MCTD, as dramatically demonstrated by their case report.

However, one important point has been overlooked by the authors and should be mentioned. Gonadotropin releasing hormone agonists [GnRH-a] may possibly provide ovarian protection against the gonadotoxic effect of chemotherapy either by ovarian suppression and/or by decreasing ovarian perfusion as it simulates a reversible prepubertal hypoestrogenic hormonal milieu, or by possible other mechanisms [2]. We have preliminarily reported, 10 years ago, 5 cases of POF in 9 SLE patients in the control group, while none of the 8 patients treated with GnRH-a suffered POF (3). Similarly, in another study, Somers and coworkers (4) described that only one woman among 20 SLE female patients in the GnRHa group developed POF compared with 6/20 (30 \%) among the controls $(P<0.05)$. In a larger group of SLE patients we have found that $\mathrm{GnRH}-\mathrm{a}$ decreases cyclophosphamide-

\footnotetext{
Z. Blumenfeld

Reproductive Endocrinology,

The Rappaport Institute \& Faculty of Medicine,

Technion-Israel Institute of Technology,

RAMBAM Health Care Campus,

Haifa 31096, Israel

Z. Blumenfeld $(\bowtie)$

Reproductive Endocrinology, Department OB/GYN,

Rappaport Research Institute,

Rambam Health Care Campus, 8 Ha'Aliyah St,

Haifa 31096, Israel

e-mail: bzeev@techunix.technion.ac.il

e-mail: z_blumenfeld@rambam.health.gov.il
}

associated gonadotoxicity and POF in young women with systemic lupus erythematosus and other autoimmune diseases. Manger and coworkers [3] started a RCT (the PREGO study) a few years ago, and we are all looking forward to its results. Therefore this treatment should be considered and recommended to every young woman before gonadotoxic chemotherapy. The authors [1] mention the possibility "...that GnRH may exacerbate autoimmune diseases, an association that merits further research ". The answer to their raised question has been supplied by others and by us $[2,4,5]$. None of our SLE or MCTD patients [2, 4] treated with GnRH-a developed any exacerbation, similar to the experience of others [5]. It may be concluded that in high risk MCTD or SLE patients, especially those with pulmonary hypertension, fertility preservation before cyclophosphamide pulses could be offered with GnRH-a and not ovarian hyperstimulation for IVF.

\section{References}

1. Sioulas VD, Gracia CR. Ovarian stimulation and embryo banking for fertility preservation in a woman with severe mixed connective tissue disease: is it safe? J Assist Reprod Genet. 2012;29:271-5.

2. Blumenfeld Z, Mischari O, Schultz N, Boulman N, Balbir-Gurman A. Gonadotropin releasing hormone agonists may minimize cyclophosphamide associated gonadotoxicity in SLE and autoimmune diseases. Semin Arthritis Rheum. 2011;41:346-52.

3. Manger K, Wildt L, Kalden JR, Manger B. Prevention of gonadal toxicity and preservation of gonadal function and fertility in young women with systemic lupus erythematosus treated by cyclophosphamide: the PREGO-Study. Autoimmun Rev. 2006;5:269-72.

4. Blumenfeld Z, Shapiro D, Shteinberg M, Avivi I, Nahir M. Preservation of fertility and ovarian function and minimizing gonadotoxicity in young women with systemic lupus erythematosus treated by chemotherapy. Lupus. 2000;9:401-5.

5. Somers EC, Marder W, Christman GM, Ognenovski V, McCune WJ. Use of a gonadotropin-releasing hormone analog for protection against premature ovarian failure during cyclophosphamide therapy in women with severe lupus. Arthritis Rheum. 2005;52:2761-7. 